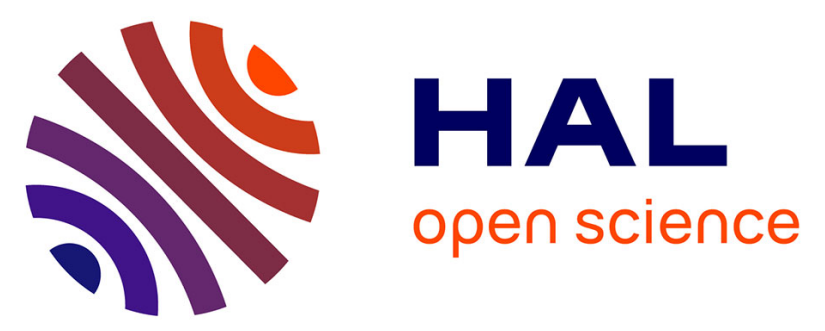

\title{
Externalizing behaviors in preadolescents: familial risk to externalizing behaviors, prenatal and perinatal risks, and their interactions
}

Cathelijne J. M. Buschgens, Sophie H. N. Swinkels, Marcel A. G. Aken, Johan Ormel, Frank C. Verhulst, Jan K. Buitelaar

\section{To cite this version:}

Cathelijne J. M. Buschgens, Sophie H. N. Swinkels, Marcel A. G. Aken, Johan Ormel, Frank C. Verhulst, et al.. Externalizing behaviors in preadolescents: familial risk to externalizing behaviors, prenatal and perinatal risks, and their interactions. European Child and Adolescent Psychiatry, 2008, 18 (2), pp.65-74. 10.1007/s00787-008-0704-x . hal-00478065

\section{HAL Id: hal-00478065 https://hal.science/hal-00478065}

Submitted on 30 Apr 2010

HAL is a multi-disciplinary open access archive for the deposit and dissemination of scientific research documents, whether they are published or not. The documents may come from teaching and research institutions in France or abroad, or from public or private research centers.
L'archive ouverte pluridisciplinaire HAL, est destinée au dépôt et à la diffusion de documents scientifiques de niveau recherche, publiés ou non, émanant des établissements d'enseignement et de recherche français ou étrangers, des laboratoires publics ou privés. 
Cathelijne J.M. Buschgens

Sophie H.N. Swinkels

Marcel A.G. van Aken

Johan Ormel

Frank C. Verhulst

Jan K. Buitelaar

\section{Externalizing behaviors in preadolescents: familial risk to externalizing behaviors, prenatal and perinatal risks, and their interactions}

Accepted: 27 March 2008

Published online: 28 June 2008

C.J.M. Buschgens, MSc. ( $\square)$

S.H.N. Swinkels, Ph.D.

J.K. Buitelaar, M.D., Ph.D.

Department of Psychiatry

Radboud University Nijmegen Medical

Centre

PO Box 9101, HP 966

6500 HB Nijmegen, The Netherlands

E-Mail: c.buschgens@psy.umcn.nl

M.A.G. van Aken, Ph.D.

Department of Developmental Psychology

Utrecht University

Utrecht, The Netherlands

J. Ormel, Ph.D.

Department of Psychiatry

University Medical Centre Groningen

Groningen, The Netherlands

F.C. Verhulst, M.D., Ph.D.

Department of Child and Adolescent

Psychiatry

Erasmus MC-Sophia

Rotterdam, The Netherlands

S.H.N. Swinkels, Ph.D.

J.K. Buitelaar, M.D., Ph.D.

Karakter Child and Adolescent Psychiatry

University Centre

Nijmegen, The Netherlands
Abstract Background Accumulating evidence indicates that there is a rich and varied interplay between persons and their environments, which strongly suggests that this involves gene-environment correlations and interactions. We investigated whether familial risk (FR) to externalizing behaviors and prenatal and perinatal risk factors, separately or in interaction with each other, predicted externalizing behaviors. Methods The subjects were 10- to 12-year-old preadolescents who were taking part in TRAILS, a large prospective populationbased cohort study $(N=2,230)$. Regression analyses were used to determine the relative contribution of FR and prenatal and perinatal risks to parent and teacher ratings of inattention, hyperactivity/impulsivity aggression, and delinquency. Results Regression models explained between 6 and $11 \%$ of the variance of externalizing behaviors. We found main effects of FR (vs. no FR), macrosomia (birth weight $>4,500 \mathrm{~g}$ ), maternal prenatal smoking (MPS), pregnancy and delivery complications (PDCs), and gender that were rather consistent across rater and outcome measures. For some outcome measures, the effect of MPS and PDCs depended on the presence of FR. These included both positive and negative interaction effects. Correlations between FR and prenatal and perinatal risks were significant but rather low. Conclusions Both main effects and interaction effects of FR and prenatal and perinatal risks contributed to externalizing behaviors in preadolescents, but all effects were of small size. Further research including use of candidate gene polymorphisms is necessary to identify the underlying neurobiological mechanisms of these main and interaction effects.

Key words externalizing behavior - familial risk prenatal and perinatal risks gene-environment interaction

\section{Introduction}

Substantial achievements have been made in the fields of psychiatric genetics and psychology [41], where accumulating evidence indicate that there is a rich and varied interplay between persons and their environments, and every reason to suppose that this involves gene-environment correlations and interactions' [42, p. 358]. This means that 'indirect genetic causal effects may also occur as result of influences on individual differences in environmental risk exposure or susceptibility to risk environments' [41, p. 997]. In the present study, we investigated whether familial 
risk to externalizing behaviors (FR) and prenatal and perinatal risk factors, separately or in interaction with each other, predicted externalizing behaviors (inattention, hyperactivity/impulsivity, aggressive and delinquent behaviors) in a large population sample of preadolescents.

\section{Genetic influences}

Numerous twin, adoption and family studies have clearly indicated that genetic influences, as they apply to individual differences in the liability to specific behaviors, are strong and pervasive but rarely determinative [41]. Different behavior genetic studies have focused on the genetic influences of specific disorders or domains, for instance, heritability estimates for attention deficit hyperactivity disorder (ADHD) are of 0.76 [15], of 0.55 for oppositional defiant disorder (ODD) and between $0.50-0.62$ for conduct disorder (CD) $[12,17]$. However, many risk factors, including genetic factors, are not disorder specific [23]. High levels of comorbidity among ADHD, ODD and CD are found [12], which is likely to be due to a substantial degree of shared genetic liability, either operating directly, or indirectly through gene-environment correlations or interactions [30]. After controlling for the overlap between internalizing and externalizing symptoms, familial risk (FR) to externalizing behaviors is specifically associated with externalizing but not with internalizing psychopathology in the offspring [35].

In line with earlier studies [13, 33, 35, 52], we used a proxy for familial risk, which was based on family history data. Since the heritability of externalizing disorders is relatively high, and the etiologic contribution of common environmental risk factors to externalizing disorders is relatively modest, we may assume that mostly genetic factor drive the FR measure. Note that this familial risk might be a consequence of both genetic and environmental factors [43].

\section{Environmental influences}

Research in behavioral genetics also demonstrates the importance of environmental influences (e.g. prenatal and perinatal risk factors) in the causation of externalizing behaviors. LBW (low birth weight, defined as $<2,500 \mathrm{~g}$ ) exerts effects on development, and is related to several externalizing problem behaviors (e.g. $[10,11,32])$. Compared with non-ADHD controls, ADHD cases were three times more likely to be born as LBW, even after controlling for potential confounders such as prenatal exposure to alcohol and cigarettes, parental ADHD, social class, and comorbid disruptive behavior disorders in parents and offspring [26]. In a twin study, the effect of LBW on child problem behavior remained after controlling for genetic or other environmental factors [51]. Though there has been a rise in the prevalence of large newborns over a few decades, and there is much evidence that fetal macrosomia (a birth weight of 4,500 $\mathrm{g}$ or more [3]) is associated with increased risk of complications both for the mother and the newborn [20], a direct causal relationship between large birth weight and external problem behavior is unknown.

Prenatal exposure to maternal smoking is associated with an increased risk of ADHD [28], ODD and $\mathrm{CD}$ [32] and broader categories of externalizing behavior [16]. Besides a dose-response relationship between maternal prenatal smoking (MPS) and externalizing behaviors $[9,25]$, the effects seem to be additional to the influence of additive genetic factors and nonshared environmental influences, and not attributable to shared rater effects, clinical referral bias, or covariation with antisocial behavior [46]. However, when studies control for genetic risk, the effect of MPS decreases substantially [24, 25] which suggests gene-environment correlation.

Risk factors associated with pregnancy and birth also affect externalizing behaviors. Prechtl and Touwen $[37,49])$ introduced the 'obstetric optimality concept', by which each deviation from the optimal condition regarding prenatal and perinatal conditions of the mother, the fetus, and the placenta was summed. A more optimal obstetric situation was related to less externalizing behavior during childhood, but not to less internalizing behavior [5]. Other researchers found that maternal bleeding, smoking, family problems, and illicit drug use during pregnancy in particular were associated with ADHD [27]. Similar results were reported in a study of ADHD children, where neonatal complications were associated with higher total and externalizing scores on the Child Behavior Checklist (CBCL [1]) [6].

\section{Gene environment correlations and interactions}

Studies of environmental effects have universally shown that there are huge individual differences in response, with some individuals hardly and some severely affected [41]. Even though genetic and prenatal and perinatal environmental factors have been implicated in the etiology of externalizing behaviors, to the best of our knowledge, there have only been a small number of behavior and molecular genetic studies that have investigated the effect of both a genetic vulnerability and prenatal and perinatal risks $[39,47]$ and MPS [22, 31, 48]. We have defined FR at a phenotypic level, which was based on the family 
history, and served as a proxy for genetic vulnerability [13, 33, 35, 52]. The availability of DNA analysis in the next future will allow us to refine our analyses by including genetic polymorphisms as risk factors.

We investigated the role of FR, prenatal and perinatal risk factors, and their correlation and interaction on the development of externalizing behaviors in a large community-based sample of preadolescents. To this end, we addressed the following hypotheses:

(1) Does FR increase the risk of externalizing behaviors?

(2) Do prenatal and perinatal risks, such as LBW, MPS, and pregnancy and delivery complications (PDCs), increase the risk of externalizing behaviors?

(3) Do FR and prenatal and perinatal risks correlate and interact to increase the risk of externalizing behaviors?

\section{Methods}

\section{Sample}

The subjects were participants of the tracking adolescents' individual lives survey (TRAILS), a prospective cohort study of Dutch preadolescents who will be measured biennially until they are at least 25 years old. The key objective of TRAILS is to chart and explain the development of mental health from preadolescence into adulthood, in terms of underlying vulnerability and environmental risk. Participants were 10-to-12 years old and lived in the three largest cities and some rural areas in the north of the Netherlands. A detailed description of the sampling procedure and methods is provided elsewhere [14].

Briefly, the present study involves the first assessment wave of TRAILS, which ran from March 2001 to July $2002[13,14,33,52]$. Of all children approached for enrollment in the study (i.e., children selected by the municipalities and attending a school that was willing to participate; $N=3,145$ children from 122 schools, with $90.4 \%$ of the schools responding), $6.7 \%$ were excluded because of incapability or language problems. Of the remaining 2,935 children, $76.0 \%$ were enrolled in the study, yielding a sample size of 2,230 . Both the child and the parent consented to participate. The mean age of the children was 11.09 years $(\mathrm{SD}=0.55) ; 50.8 \%$ were girls; $10.3 \%$ were children who had at least one parent born in a nonWestern country; and $32.6 \%$ of children had parents with a low educational level (i.e., a lower track of secondary education was the highest level attained). Responders and nonresponders did not differ with respect to the prevalence rates of psychopathology and associations between sociodemographic variables and mental health outcomes [14].

\section{Data collection}

Well-trained interviewers visited one of the parents (preferably the mother, 95.6\%) at home to administer an interview covering a wide range of topics, including the child's developmental history and somatic health, parental psychopathology, and care utilization. Besides the interview, the parent was also asked to fill out a written questionnaire. Children were evaluated at school, where they filled out questionnaires in groups, under the supervision of TRAILS assistants, and were assessed individually. Teachers were asked to fill out a brief questionnaire for each TRAILS child in their class. Measures that were used in the present study are described below.

\section{Familial risk to externalizing behaviors (FR)}

Five dimensions of lifetime parental psychopathology were assessed (depressive disorders, anxiety disorders, substance dependence, antisocial behavior, and psychosis), using the TRAILS family history interview (FHI), which was administered at the parent interview [35]. Each dimension was introduced with a vignette describing the main DSM-IV [4] characteristics of the psychopathology, followed by a series of questions to assess lifetime occurrence, professional treatment, and medication use. Both biological parents were assessed during the interview, using a single informant, typically the mother. For each spectrum, the parents were assigned to one of the categories $0=$ (probably) never had an episode, $1=$ (probably) yes, or $2=$ (probably) yes and treatment and/or medication were provided. For antisocial behavior, the last category was: $2=$ (probably) yes and picked up by the police. Prevalence rates in mother and fathers respectively were, for depression: 27 and 15\%; for anxiety: 16 and 6\%; for substance dependence: 3 and 7\%; and for antisocial behaviour: 3 and 7\%. The FHI rates were by and large comparable to the CIDI-DSMIV lifetime rates obtained by direct interviewing in NEMESIS [8]; the exception being fathers' rates for anxiety disorder and substance dependence that were $40 \%$ too low $[35,52]$. We did not focus on parental psychosis, depressive and anxiety disorders.

The construction of FR was based on the presence reported path coefficients regarding substance abuse and antisocial behavior by Kendler et al. [23], who preformed multivariate twin modeling to investigate the structure of genetic risk for common psychiatric 
and substance use disorders. First, we combined the coefficients reported by Kendler et al. [23] for alcohol dependence and drug abuse/dependence to create the variable SAD (substance abuse/dependence), and likewise we created the variable ASB (antisocial behavior) by combining the coefficients for antisocial behavior and conduct disorder. Subsequently, FR scores were computed by filling in the following regression equation: $\mathrm{FR}$ to externalizing behaviors $=$ SAD mother + SAD father + ASB mother + ASB father, FR ranged from 0 to 8 (skewness 3.78, kurtosis, 17.63). To enhance comparison with other TRAILS reports $[33,52]$ missing values $(N=67)$ were replaced by the sample mean $(0.18)$. Two groups were created on the basis of the distribution of FR (Total $N=2,230)$; children with no FR $(82.2 \%)$ and children with FR (17.8\%). In the regression analyses these two groups were used as a dummy variable.

\section{Prenatal and perinatal risks}

Several prenatal and perinatal risks were assessed by means of the TRAILS Family History Interview, administered at the parent interview. Children who weighed less than 5 pounds $(<2,500 \mathrm{~g})$ were considered as low birth weight (LBW; 3.6\%), and children weighing 9 pounds or more $(\geq 4,500 \mathrm{~g})$ as macrosomic $(6.5 \%)$ (total $N=2,132)$. This cut-off is based on the ACOG definition of macrosomia [3].

MPS was estimated by asking the informant whether, and if so how much, the mother had smoked during pregnancy: $0=$ not at all, $1=$ a few times, less than 1 cigarette a day, $2=1-10$ cigarettes a day, $3=11-20$ cigarettes a day, $4=1-2$ packets a day, and $5=$ more than 2 packets a day. The categories were recoded into three groups: non-smokers (69.5\%), mild smokers ( $\leq 10$ cigarettes a day; $23.6 \%$ ), and heavy smokers ( $>10$ cigarettes a day; 6.9\%); data were available for 2,168 mothers. In accordance with the literature $[9,25]$, the cut off between some and moderate/severe risk was set on 10 cigarettes a day.

An index of PDCs was composed by adding the score for the presence of pregnancy complications (i.e. physical, social or psychological problems during pregnancy), complicated deliveries (i.e. breech presentation, Caesarean section) and hospitalization of the mother (i.e. due to physical problems, postnatal depression) or child (i.e. lack of oxygen, blood transfusion, jaundice) $[18,27]$. This PDC score ranged between 0 and $14(m=1.87, S D=2.19)$. If no information was available for six or more items, cases were excluded from further analyses. Three groups were created on the basis of the distribution of PDCs and our aim to demarcate a top $10 \%$ with high PDCs (total $N=2,186)$ : no complications (37.6\%), between 1 and
4 complications $(50.0 \%)$, and 5 or more complications $(12.4 \%)$.

\section{Externalizing behaviors}

Externalizing behaviors were assessed with the child behavior checklist (CBCL), one of the most commonly used questionnaires in current child and adolescent psychiatric research $[1,53]$. It contains a list of 112 behavioral and emotional problems which parents can rate as $0=$ not true, $1=$ somewhat or sometimes true, or $2=$ very often true in the past 6 months. In addition to the CBCL, we administered the teacher's checklist of psychopathology (TCP). The TCP contains descriptions of problem behaviors corresponding to the syndromes scored with Achenbach's teacher report form [14]. Response options range from 0 (not applicable) to 4 (very clearly or frequently applicable). In this study we focused on the CBCL syndromes attention problems $(\alpha=0.81)$, aggressive behavior $(\alpha=0.89)$, and delinquent behavior $(\alpha=0.68)$. Consistent with other reports [2], the agreement between parent-reported and teacherreported problems was only moderate $(r=0.47$ for inattention, $r=0.37$ for impulsivity/hyperactivity, $r=0.32$ for aggression and $r=0.27$ for delinquency). We feel that the two informants perceive different aspects of problem behavior and that differences between informants are meaningful.

\section{Statistical analysis}

Two dummies were made for each of the predictors that consisted of three categories. For birth weight, the high and the low group were compared to the middle group (normal birth weight). This enables us to contrast both the macrosomic children and the LBW children separately to children with a normal birth weight. For the predictors MPS and PDCs, the first dummy included the contrast between the absence vs. the presence (regardless of the level) of the predictor. The second dummy included the contrast between the absence/mild presence vs. the extreme presence of the predictors, this contrast thus enabled us to examine whether a dose response effect was present.

To obtain comparable regression coefficients, z-scores were used for all dependent variables. Associations between variables were examined by means of Pearson correlations. Regression analyses were used to determine the relative contributions of FR, birth weight, MPS, PDCs, and gender to parents' and teachers' ratings of inattention, hyperactivity/impulsivity, aggression and delinquency. Interaction terms 
between FR and prenatal and perinatal risks, and sex (as a covariate) were also entered into the regression models. No multicollinearity was present in our data (greatest VIF value was 4.59 for FR).

All analyses were performed using the Statistical Package for the Social Sciences (SPSS for Windows, version 14.0).

\section{Results}

\section{Bivariate correlation between predictors and externalizing behaviors}

The (Pearson) bivariate correlations between the predictors and the dependent measures of externalizing behaviors are summarized in Table 1. Both FR and MPS were positively associated with all dependent measures as reported by parents and teachers. LBW was negatively correlated with parent-rated inattention and aggression. PDCs were positively correlated with inattention reported by parents and teachers, and with aggression and delinquency reported by parents. FR was positively correlated with MPS, and negatively with LBW. Thus person-environment correlations were present: children with a higher FR had been exposed to more prenatal and perinatal risks.

\section{Multivariate models of inattention, hyperactivity and impulsivity}

Multiple linear regression analysis showed that FR, prenatal and perinatal risks and gender together explained $8 \%$ of the variance in parent reported inattention (see Table 2). There was a main effect of FR (vs. no FR). Main effects were further found for MPS, PDCs (both at mild and severe levels), and gender, with boys having higher scores than girls. The main effects for FR, MPS and PDCs are shown in Fig. 1.

Table 1 Bivariate correlations between predictors and externalizing behaviors (standardized score)

\begin{tabular}{|c|c|c|c|c|c|c|c|c|}
\hline Variable & FR & CBCL-inatt & TPC-inatt & TCP-HA/IMP & CBCL-aggr & TCP-aggr & CBCL-deli & TCP-deli \\
\hline FR & - & $0.15^{* *}$ & $0.12^{* *}$ & $0.12^{* *}$ & $0.13^{* *}$ & $0.14^{* *}$ & $0.15^{* *}$ & $0.13^{* *}$ \\
\hline LBW \& NBW & $-0.05^{*}$ & $-0.08^{* *}$ & NS & NS & $-0.06^{*}$ & NS & NS & NS \\
\hline HBW \& NBW & NS & NS & NS & NS & NS & NS & NS & NS \\
\hline MPS & $0.20^{* *}$ & $0.14^{* *}$ & $0.16^{* *}$ & $0.14^{* *}$ & $0.10^{* *}$ & $0.13^{* *}$ & $0.14^{* *}$ & $0.13^{* *}$ \\
\hline PDCs & NS & $0.13^{* *}$ & $0.06^{* *}$ & NS & $0.10^{* *}$ & NS & $0.06^{* *}$ & NS \\
\hline
\end{tabular}

CBCL child behavior checklist, TCP teacher's checklist of psychopathology, Inatt inattention, HA/IMP hyperactivity/impulsivity, Aggr aggression, Deli Delinquency, FR familial risk (for externalizing behavior), $L B W$ low birth weight $(<2,500 \mathrm{~g}), N B W$ normal birth weight, $H B W$ high birth weight/macrosomia $(>4,500 \mathrm{~g}) ; M P S \mathrm{maternal}$ prenatal smoking, $P D C$ s pregnancy and delivery complications, NS not significant

${ }^{*} P<0.05 ;{ }^{* *} P<0.01(2$-tailed)

Table 2 Multiple linear regression analyses, for each separate (standardized) dependent variable and informant

\begin{tabular}{|c|c|c|c|c|c|c|c|}
\hline \multirow[t]{2}{*}{ Variable } & \multicolumn{7}{|l|}{$\beta$} \\
\hline & $\begin{array}{l}\text { CBCL-inatt } \\
R^{2}=0.08\end{array}$ & $\begin{array}{l}\text { TPC-inatt } \\
R^{2}=0.09\end{array}$ & $\begin{array}{l}\text { TCP-HA/IMP } \\
R^{2}=0.11\end{array}$ & $\begin{array}{l}C B C L \text {-aggr } \\
R^{2}=0.06\end{array}$ & $\begin{array}{l}\text { TCP-aggr } \\
R^{2}=0.10\end{array}$ & $\begin{array}{l}\text { CBCL-deli } \\
R^{2}=0.08\end{array}$ & $\begin{array}{l}\text { TCP-deli } \\
R^{2}=0.07\end{array}$ \\
\hline Boys vs. girls & $0.17^{* *}$ & $0.20^{* *}$ & $0.28^{* *}$ & $0.13^{* *}$ & $0.24^{* *}$ & $0.19^{* *}$ & $0.18^{* *}$ \\
\hline FR vs. no FR & $0.13^{* *}$ & NS & NS & $0.14^{* *}$ & NS & $0.15^{* *}$ & $0.10^{*}$ \\
\hline LBW vs. NBW & NS & NS & NS & NS & NS & NS & NS \\
\hline HBW vs. NBW & NS & $0.07^{* * *}$ & $0.09^{* *}$ & $0.06^{*}$ & $0.08^{* *}$ & NS & $0.09^{* *}$ \\
\hline MPS vs. MPS & $0.12^{* *}$ & $0.14^{* *}$ & $0.10^{* *}$ & $0.08^{* *}$ & $0.10^{* *}$ & $0.11^{* *}$ & $0.07^{* *}$ \\
\hline Severe MPS vs. no/ some MPS & NS & NS & $0.06^{*}$ & NS & $0.07^{*}$ & NS & $0.10^{* *}$ \\
\hline PDCs vs. no PDCs & $0.06^{*}$ & $0.06^{*}$ & NS & NS & NS & NS & NS \\
\hline Severe PDCs vs. no/some PDCs & $0.06^{*}$ & NS & NS & $0.07^{* *}$ & NS & $0.05^{*}$ & NS \\
\hline FR vs. no $F R{ }^{*} L B W$ vs. NBW & NS & NS & NS & NS & NS & NS & NS \\
\hline FR vs. no $F R *$ HBW vs. NBW & NS & NS & NS & NS & NS & NS & NS \\
\hline FR vs. no $F R$ * MPS vs. no MPS & NS & $-0.11^{* *}$ & $-0.08^{*}$ & NS & NS & NS & NS \\
\hline FR vs. no FR * severe MPS vs. no/some MPS & NS & $0.09^{* *}$ & $0.06^{*}$ & NS & NS & NS & NS \\
\hline FR vs. no $F R$ * PDCs vs. no PDCs & NS & NS & NS & NS & NS & NS & NS \\
\hline FR vs. no $F R^{*}$ severe PDCs vs. no/ some PDCs & NS & NS & NS & $-0.07^{*}$ & NS & NS & Ns \\
\hline
\end{tabular}

$C B C L$ child behavior checklist, TCP teacher's checklist of psychopathology, Inatt Inattention, HA/IMP hyperactivity/impulsivity, Aggr aggression, Deli delinquency, $F R$ familial risk for externalizing behavior, $L B W$ low birth weight $(<2,500 \mathrm{~g}), N B W$ normal birth weight, $H B W$ high birth weight/macrosomia $(>4,500 \mathrm{~g}), M P S \mathrm{maternal}$ prenatal smoking, $P D C s$ pregnancy and delivery complications, NS not significant

${ }^{*} P<0.05,{ }^{* *} P<0.01$ (two-tailed) 


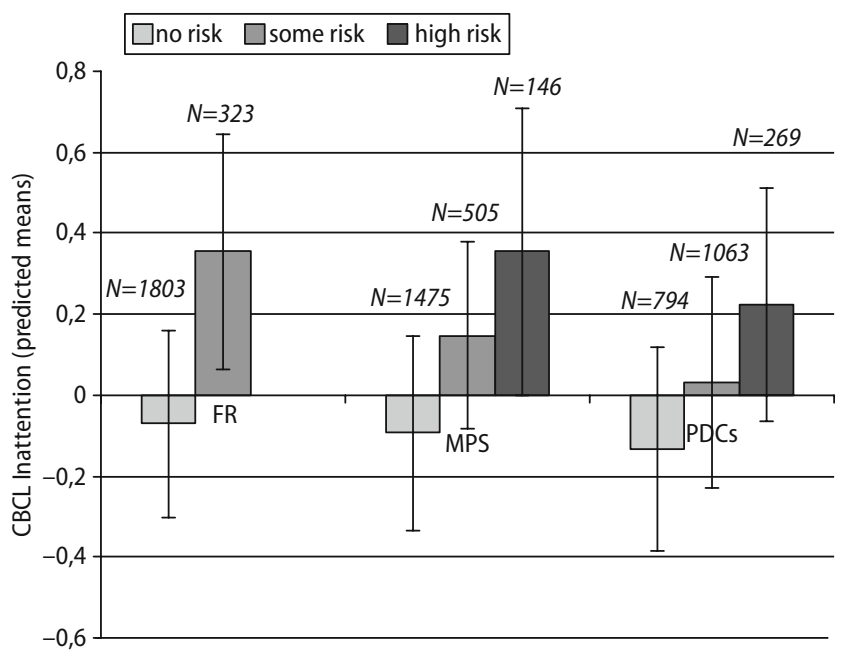

Fig. 1 Main effects of familial risk (FR), maternal prenatal smoking (MPS) and pregnancy and delivery complications (PDCs) as predictors for parent-reported inattention. The figure presents predicted values (and sd) from the multivariate model for the main effects of FR, MPS and PDCs. Group size and composition are different for each of these predictors. Note: FR consists of two groups: children with no FR and children with FR

Table 2 also shows that the model explained about $9-11 \%$ of teacher rated inattention and hyperactivity/ impulsivity. Main effects were found for macrosomia, MPS (at both levels for hyperactivity/impulsivity), PDCs (vs. no PDCs, only for parent rated inattention) and male gender. No main effects of FR was found.

Four interactions effects were found for teachers' reported inattention and hyperactivity/ impulsivity. These interaction effects refer to FR and MPS at different levels. The first two were between FR (vs. no FR) and MPS (vs. no MPS) for teacher' reported inattention and hyperactivity/impulsivity. As shown in Table 2, this negative interaction effect indicates that the effect of MPS was stronger in children with no FR than in children with FR. The second two positive interaction effects were between FR (vs. no FR) and severe MPS (vs. no/some MPS) for teacher' reported inattention and hyperactivity/impulsivity, indicating that the effect of severe MPS was stronger for children with no FR than in children with FR. As illustrated in Fig. 2, these effects together reflect that MPS has initially at lower levels a stronger effect in the absence than in the presence of FR. However, at more severe levels of MPS this negative interaction is turned into a positive interaction and overruled.

\section{Multivariate models of aggressive behavior}

The models explained around $6 \%$ and $10 \%$ of the variance in aggressive behavior reported by parents and teachers, respectively. Main predictors of aggression, as measured with the CBCL, were FR,

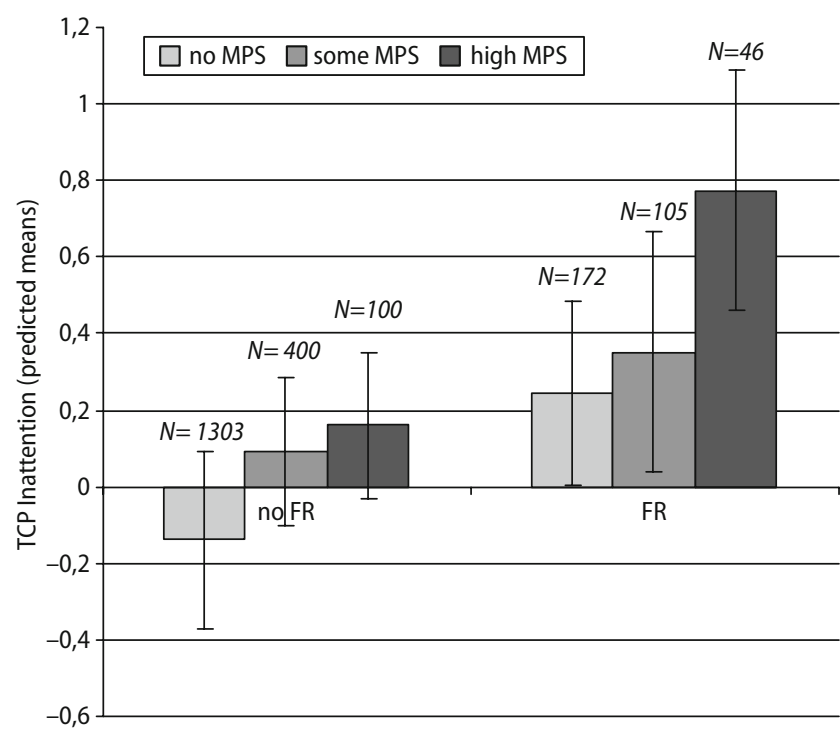

Fig. 2 The integration of two interaction effects between familial risk (FR) and maternal prenatal smoking (MPS) as predictors for teacher-reported inattention

macrosomia, MPS (vs. no MPS), severe PDCs, and gender. Main predictors of teacher-rated aggression were macrosomia, MPS (both at mild and severe levels), and gender. One (negative) interaction effects was found for parent-rated aggression. This one concerns the effect between FR and severe PDCs: the effect of severe PDCs is stronger for children without FR than for children with FR.

\section{Multivariate models of delinquent behavior}

FR, prenatal and perinatal risks, and gender explained about 7 and $8 \%$ of the variance in delinquent behavior reported by parents and teachers. Several main effects but no significant interactions were found. Parentrated delinquency was predicted by FR, MPS (vs. no MPS), severe PDCs, and gender. Main risk factors for teacher-reported delinquent behavior were FR, macrosomia, MPS (both at mild and severe levels), and gender.

\section{Discussion}

In line with two earlier papers based on the TRAILS dataset [13, 35, 52], we found FR to externalizing behaviors to be a main predictor of externalizing behaviors in preadolescents, as evidenced by significant bivariate correlations between FR and all seven dependent measures of externalizing behavior, and by a significant independent contribution to parent-rated inattention, aggression and delinquency and teacherrated delinquency in the multivariate analyses. 
Several prenatal and perinatal risk factors were found to be main predictors of externalizing behaviors, even after adjustment for other predictors in multivariate models. Although most studies have focused on LBW or even extreme LBW in relation to behavioral and psychiatric sequelae $[10,11]$, we were interested in both LBW and macrosomia. As expected, we found that, LBW was correlated with more parent-rated inattention and aggression. Since several studies suggest that LBW is also associated with internalizing problems [19] and depression [44], LBW does not seem to be a disorder-specific risk factor. In addition, the fact that LBW was not a risk factor of inattention may be due to other environmental factors that might moderate this relationships such as urban vs. suburban communities [11] and maternal warmth [50]. As a novel finding, macrosomia was a risk factor for one parent- and all teacher-reported externalizing behaviors. A possible explanation for this finding may be that macrosomia is related to adverse perinatal, neonatal and maternal outcomes (e.g. [7, 20, 29, 34]), and that these adversities are related to more problem behavior (e.g. [5, 6, 27]). Another possibility is that large babies are also more likely to have a large body size in childhood [36], and a large body size at age 3 was related to increased aggression at age 11 years [38]. Together these results indicate that the relationship between birth weight and externalizing problems is curvilinear, with both macrosomia and LBW contributing to higher levels of externalizing behaviors.

MPS was, as expected e.g. [16], also a main risk factor for all parent- and teacher-reported externalizing behaviors, even after adjusting for the effect of FR. MPS was associated with teacher-reported hyperactivity/impulsivity, aggression, and delinquency in a dose-dependent manner, with children who were prenatally exposed to more than 10 cigarettes a day showing more hyperactivity, aggression, and delinquency than children who were prenatally exposed to fewer cigarettes. This is also in line with other research e.g. $[9,25]$.

PDCs were directly related with the parent-reported inattention, aggression and delinquency and with teacher-reported inattention in multivariate analyses. These effects of PDCs, and especially a high level of PDCs, on all three parent-reported measures of externalizing behaviors survived in the multivariate analyses. Children with five or more PDCs were at more risk of some externalizing behaviors than children who had no or less PDCs. Boys showed more externalizing behaviors than girls.

Our study provided a unique opportunity to examine the evidence for the presence of personenvironment correlations and interactions on behavioral problems. FR was significantly correlated with LBW, MPS, and the presence and severity of PDCs. For the interpretation of person-environment interaction, researchers will need to ensure that the environmental risk in question is not genetically mediated. When genes and environment are highly correlated, person-environment interactions may in fact represent gene-gene interactions, where the prenatal/perinatal risk, is in fact a marker for genetic risk [21]. Since we only found weak person-environment correlations, which indicate that there is some control of FR on the exposure to these prenatal and perinatal risk factors, we can be confident that our findings represent true person-environment interaction. In addition, we also found that prenatal and perinatal risks predicted externalizing behaviors, even when FR was controlled for; this suggests that some of these risks are truly environmental. Nevertheless, a number of recent twin studies have shown that the adverse effects of MPS on symptoms of conduct disorder [25,45] or ADHD [24] decrease or even disappear when the analyses are controlled for genetic effects and also other confounders are taken into account. A possible explanation for this difference may be explained by the fact that the referred studies involve a twin design.

When examining person-environment interactions, we entered six interaction terms in seven multivariate analyses. Out of these 42 tests performed, 5 interactions terms were found to be significant at the $P=0.05$ level. $(n=42$, test proportion $0.05, P>0.05$ by binomial test). Although the number of significant interaction is at chance level, the four effects between FR and (severe) prenatal smoking are within the same domain, and are partially in line with molecular genetic studies that focussed on the effects of maternal prenatal smoking and a genetic vulnerability $[22,31,48]$.

We like to note that we found both positive and negative interaction effects. The positive effects indicate that the influence of environmental risk factors is stronger in the presence of FR. This is in line with the stress-vulnerability model of psychopathology. In contrast, negative interaction effects entail that the influence of environmental factors is largest in the absence of FR. This model is less well-known and may be called the environment-permissiveness model. Possible explanations for this environment-permissiveness model are that strong environmental risk factors may overrule the more subtle influence of individual vulnerability factors and that the influence of genetic vulnerability factors is strongest in the absence rather than the presence of the environmental risk factor.

Differences and similarities in the results across parents and teacher reports of externalizing behaviors can generally be explained in several ways: risk factors 
that seem to affect all types of externalizing behavior, independent of the rater (e.g. MPS, gender), risk factors which seems to affect behaviors in specific domains (e.g. FR, PDCs) and risk factors which seems to be 'disorder' specific (e.g. interaction effects between FR and MPS). Future studies should look into the mechanisms underlying these findings.

\section{Limitations}

This is the first study to combine the effects of FR and prenatal and perinatal risk factors in an epidemiological sample, without shared rater effects. However, our study had several potential limitations. Firstly, FR to externalizing behaviors was defined at a phenotypic level and was based on family history as a proxy for genetic vulnerability. With the caveat in mind that FR may reflect both genetic and environmental influences, the availability of DNA analysis in the next future will allow us to refine our analyses by including genetic polymorphisms as risk factors. Secondly, the use of family history interviews, as compared with direct interviews of relatives, may have led to underreporting of lifetime parental psychopathology, and thus underestimation of associations is possible [35]. However, except for father's rate for substance dependence, our prevalence rates were comparable to life time rates obtained by direct interviewing [8]. Thirdly, we investigated preadolescents and results may differ for other developmental periods. Future studies should examine whether the main and interaction effects found are also relevant to the prediction of externalizing problems in older children. Lastly, we obtained retrospective information on prenatal and perinatal risk factors. Underreporting cannot be excluded, although studies have shown that, after 4-9 years, the agreement between retrospective reports and information for medical records was generally 'very good', including birth weight, MPS and complications in pregnancy and labour [40].

\section{Clinical implications}

Because children who are genetically vulnerable to externalizing behaviors are at increased risk of showing more externalizing (problem) behavior, particular in conjunction with prenatal and perinatal risk factors, knowledge of a family history of alcohol and drug abuse/dependence and antisocial behavior may be used to help clinicians to prioritize cases. In addition, mothers, especially from genetically vulnerable families, who experience pregnancy and labour complications should be monitored as well; these risk should be limited as much as possible.

This study has mainly been descriptive in how FR and prenatal and perinatal risk factors are associated and interact with externalizing behaviors. The neurobiological mechanisms underlying the interactions between FR and environmental risks, such as low birth weight, macrosomia, MPS and PDCs, are largely unknown. Since both ends on the continuum of birth weight seem to be associated with more problem behavior, it is necessary to monitor the child's growth, and start from the prenatal period. Studies that focus on modelling of developmental trajectories, neuropsychological functions and brain activity/structure offer the opportunity to deepen our understanding of pathways to health and illness across childhood and adolescence and the relevant neurobiological mechanisms underneath, and may give more leads for prevention and intervention.

\footnotetext{
Acknowledgments This research is part of TRAILS, a multicenter cohort study involving the University of Groningen, the Erasmus Medical Center of Rotterdam, the Vrije University of Amsterdam, the Radboud University Nijmegen Medical Centre, and the Trimbos Institute and the University of Leiden, the Netherlands. TRAILS is financially supported by grants from the Netherlands Organization for Scientific Research (GB-MW 940-38-011, GB-MAG 480-01-006, ZonMw 100.001.001; NWO-175.010.2003.005) and the Department of Justice, and by the participating centers. C.J.M. Buschgens is supported by Radboud University Nijmegen Medical Centre.
}

\section{References}

1. Achenbach TM (1991) Manual for the child behavior checklist/4-18 and 1991 profile. University of Vermont, Burlington

2. Achenbach TM, Mc Conaughy $\mathrm{SH}$, Howell CT (1987) Child/adolescent behavioral and emotional problems: implications of cross-informant correlations for situational specificity. Psychol Bull 101:213-232
3. American College of Obstetricians and Gynecologists (1991) Fetal macrosomia. Technical Bulletin 159. ACOG, Washington

4. American Psychiatric Association (1994) Diagnostic and statistical manual of mental disorder, 4th edn. American Psychiatric Association, Washington
5. Batstra L, Hadders-Algra M, Ormel J, Neeleman J (2004) Obstetric optimality and emotional problems and substance use in young adulthood. Early Hum Dev 80:91-101

6. Ben Amor L, Grizenko N, Schwartz G, Lageix P, Baron C, Ter-Stepanian M, Zappitelli M, Mbekou V, Joober R (2005) Perinatal complications in children with attention-deficit hyperactivity disorder and their unaffected siblings. J Psychiatry Neurosci $30: 120-126$ 
7. Bérard J, Dufour P, Vinatier D, Subtil S, Vanderstichele S, Monnier JC, Puech F (1998) Fetal macrosomia: risk factors and outcome: a study of the outcome concerning 100 cases $>4,500$ g. Eur J Obstet Gynecol Reprod Biol 77:51-59

8. Bijl RV, Ravelli A, Van Zessen G (1998) Prevalence of psychiatric disorder in the general population: results of The Netherlands mental health survey and incidence study (NEMESIS). Soc Psychiatry Psychiatr Epidemiol 33:587-595

9. Brennan PA, Grekin ER, Mortensen EL, Mednick SA (2002) Relationship of maternal smoking during pregnancy with criminal arrest and hospitalization for substance abuse in male and female adult offspring. Am J Psychiatry 159:48-54

10. Breslau N, Brown GG, DelDotto JE, Kumar S, Ezhuthachan S, Andreski P, Hufnagle KG (1996) Psychiatric sequelae of low birth weight at 6 years of age. J Abnorm Child Psychol 24:385-400

11. Breslau N, Chilcoat HD (2000) Psychiatric sequelae of low birth weight at 11 years of age. Biol Psychiatry 47:1005-1011

12. Burt SA, Krueger RF, McGue M, Iacono W (2003) Parent-child conflict and the comorbidity among childhood externalizing disorders. Arch Gen Psychiatry 60:505-513

13. Buschgens CJM, Van Aken MAG, Swinkels SHN, Ormel J, Verhulst F, Buitelaar JK (submitted) Externalizing behaviors in preadolescents: familial risk and perceived parenting styles

14. De Winter AF, Oldehinkel AJ, Veenstra R, Brunnekreef JA, Verhulst FC, Ormel J (2005) Evaluation of non-response bias in mental health determinants and outcomes in a large sample of pre-adolescents. Eur J Epidemiol 20:173-181

15. Faraone SV, Perlis RH, Doyle AE, Smoller JW, Goralnick JJ, Holmgren MA, Sklar P (2005) Molecular genetics of attention-deficit/hyperactivity disorder. Biol Psychiatry 57:1313-1323

16. Fergusson DM, Woodward LJ, Horwood LJ (1998) Maternal smoking during pregnancy and psychiatric adjustment in late adolescence. Arch Gen Psychiatry 55:721-727

17. Gelhorn HL, Stallings MC, Young SE, Corley RP, Rhee SH, Hewitt JK (2005) Genetic and environmental influences on conduct disorder: symptom, domain and full-scale analyses. J Child Psychol Psychiatry 46:580-591

18. Gillberg C (1995) Clinical child neuropsychiatry. Cambridge University Press, Cambridge
19. Grunau RE, Whitfield MF, Fay TB (2004) Psychosocial and academic characteristics of extremely low birth weight ( $\geq 800 \mathrm{~g}$ ) adolescents who are free of major impairment compared with term-born control subjects. Pediatrics 114:e725-e732

20. Hendriksen T (2008) The macrosomic fetus: a challenge in current obstetrics. Acta Obstet Gynecol Scand 87:134-145

21. Jaffee SR, Caspi A, Moffitt TE, Dodge KA, Rutter M, Taylor A, Tully LA (2005) Nature $\times$ nurture: genetic vulnerabilities interact with physical maltreatment to promote conduct problems. Dev Psychopathol 17:67-84

22. Kahn RS, Khoury J, Nichols WC, Lanphear BP (2003) Role of dopamine transporter genotype and maternal prenatal smoking in childhood hyperactive-impulsive, inattentive, and oppositional behaviors. J Pediatr 143:104-110

23. Kendler KS, Prescott CA, Myers J, Neale MC (2003) The structure of genetic and environmental risk factors for common psychiatric and substance use disorders in men and women. Arch Gen Psychiatry 60:929-937

24. Knopik VS, Sparrow EP, Madden PA, Bucholz KK, Hudziak JJ, Reich W, Slutske WS, Grant JD, McLaughlin TL, Todorov A, Todd RD, Heath AC (2005) Contributions of parental alcoholism, prenatal substance exposure, and genetic transmission to child ADHD risk: a female twin study. Psychol Med 35:625-635

25. Maughan B, Taylor A, Caspi A, Moffitt TE (2004) Prenatal smoking and early childhood conduct problems: testing genetic and environmental explanations of the association. Arch Gen Psychiatry 61:836-843

26. Mick E, Biederman J, Prince J, Fischer MJ, Faraone SV (2002) Impact of low birth weight on attention-deficit hyperactivity disorder. J Dev Behav Pediatr 23:16-22

27. Milberger S, Biederman J, Faraone SV, Guite J, Tsuang MT (1997) Pregnancy, delivery and infancy complications and attention deficit hyperactivity disorder: issues of gene-environment interaction. Biol Psychiatry 41:65-75

28. Milberger S, Biederman J, Faraone SV, Jones J (1998) Further evidence of an association between maternal smoking during pregnancy and attention deficit hyperactivity disorder: findings from a high-risk sample of siblings. J Clin Child Psychol 27:352-358

29. Mocanu EV, Greene RA, Byrne BM, Turner MJ (2000) Obstetric and neonatal outcome of babies weighing more than $4.5 \mathrm{~kg}$ : an analysis by parity. Eur J Obstet Gynecol Reprod Biol 92:229-233
30. Nadder TS, Rutter M, Silberg JL, Maes HH, Eaves LJ (2002) Genetic effects on the variation and covariation of attention deficit-hyperactivity disorder (ADHD) and oppositional-defiant disorder/conduct disorder (Odd/CD) symptomatologies across informant and occasion of measurement. Psychol Med 32:39-53

31. Neuman RJ, Lobos E, Reich W, Henderson CA, Sun LW, Todd RD (2007) Prenatal smoking exposure and dopaminergic genotypes interact to cause a severe ADHD subtype. Biol Psychiatry 61:1320-1328

32. Nigg JT, Breslau N (2007) Prenatal smoking exposure, low birth weight, and disruptive behavior disorders. J Am Acad Child Adolesc Psychiatry 46:362-369

33. Oldehinkel AJ, Veenstra R, Ormel J, De Winter AF, Verhulst FC (2006) Temperament, parenting, and depressive symptoms in a population sample of preadolescents. J Child Psychol Psychiatry 47:684-695

34. Oral E, Cağdas A, Gezer A, Kaleli S, Aydinli K, Öçer F (2001) Perinatal and maternal outcomes of fetal macrosomia. Eur J Obstet Gynecol Reprod Biol 99:167-171

35. Ormel J, Oldehinkel AJ, Ferinand RF, Hartman CA, De Winter AF, Veenstra R, Vollebergh W, Minderaa R, Buitelaar JK, Verhulst FC (2005) Internalizing and externalizing problems in adolescence: general and dimension-specific effects of familial loadings and preadolescent temperament traits. Psychol Med 35:1825-1835

36. Parsons TJ, Power C, Logan S, Summerbell CD (1999) Childhood predictors of adult obesity: a systematic review. Int J Obes Relat Metab Disord 8:s1-s107

37. Prechtl HF (1980) The optimality concept. Early Hum Dev 4:201-205

38. Raine A, Reynolds C, Venables PH, Mednick SA, Farrington DP (1998) Fearlessness, stimulation-seeking, and large body size at age 3 years as early predispositions to childhood aggression at age 11 years. Arch Gen Psychiatry $55: 745-751$

39. Rice F, Harold GT, Thapar A (2006) The effect of birth-weight with genetic susceptibility on depressive symptoms in childhood and adolescence. Eur Child Adolesc Psychiatry 15:383-391

40. Rice F, Lewis A, Harols G, Van den Bree M, Boivin M, Hay DF, Owen MJ, Thapar A (2006) Agreement between maternal report and antenatal records for a range of pre and peri-natal factors: the influence of maternal and child characteristics. Early Hum Dev 83:497-504 
41. Rutter M (2002) The interplay of nature, nurture, and developmental influences: the challenge ahead for mental health. Arch Gen Psychiatry 59:9961000

42. Rutter M, Dunn J, Plomin R, Simonoff E, Pickles A, Maughan B, Ormel J, Meyer J, Eaves L (1997) Integrating nature and nurture: implications of person-environment correlations and interactions for developmental psychopathology. Dev Psychopathol 9:335-364

43. Rutter M, Silberg J, O'Connor T, Simonoff E (1999) Genetics and child psychiatry: II empirical research findings. J Child Psychol Psychiatry 40:1955

44. Saigal S, Pinelli J, Hoult L, Kim MM, Boyle M (2003) Psychopathology and social competencies of adolescents who were extremely low birth weight. Pediatrics 111:969-975

45. Silberg J, Parr T, Neale MC, Rutter M, Angold A, Eaves LJ (2003) Maternal smoking during pregnancy and risk to boys' conduct disturbance: an examination of the causal hypothesis. Biol Psychiatry 53:130-135
46. Thapar A, Fowler T, Rice F, Scourfield J, Van Den Bree M, Thomas H, Harold G, Hay D (2003) Maternal smoking during pregnancy and attention deficit hyperactivity disorder symptoms in offspring. Am J Psychiatry 160:19851989

47. Thapar A, Langley K, Fowler T, Rice F, Turic D, Whittinger N, Aggleton J, Van Den Bree M, Owen M, O'Donovan M (2005) Catechol O-methyltransferase gene variant and birth weight predict early-onset antisocial behavior in children with attention-deficit/hyperactivity disorder. Arch Gen Psychiatry 62:1275-1278

48. Todd RD, Neuman RJ (2007) Gene-environment interactions in the development of combined type ADHD: evidence for synapse-based model. Am J Med Genet B Neuropsychiatr Genet Part B 144:971-975

49. Touwen BC, Huisjes HJ, Jurgens-van der Zee AD, Bierman-van Eendenburg ME, Smrkovsky M, Olinga AA (1980) Obstetrical condition and neonatal neurological morbidity. An analysis with the help of the optimality concept. Early Hum Dev 4:207-228
50. Tully LA, Arseneault L, Caspi A, Moffitt TE, Morgan J (2004) Does maternal warmth moderate the effects of birth weight on twins' attention-deficit/ hyperactivity disorder (ADHD) symptoms and low IQ? J Consult Clin Psychol 72:218-226

51. Van Os J, Wichers M, Danckaerts M, Van Gestel S, Derom C, Vlietinck R (2001) A prospective twin study of birth weight discordance and child problem behavior. Biol Psychiatry 50:593-599

52. Veenstra R, Lindenberg S, Oldehinkel AJ, De Winter AF, Ormel J (2006) Temperament, environment, and antisocial behavior in a population sample of preadolescent boys and girls. Int J Behav Dev 30:422-432

53. Verhulst FC, Achenbach TM (1995) Empirically based assessment and taxonomy of psychopathology: cross-cultural applications. Eur Child Adolesc Psychiatry 4:61-76 